\title{
Patterns in vertical movements of black rockfish Sebastes melanops
}

\author{
S. J. Parker ${ }^{1,2, *}$, J. M. Olson ${ }^{1}$, P. S. Rankin ${ }^{1}$, J. S. Malvitch ${ }^{1}$ \\ ${ }^{1}$ Oregon Department of Fish and Wildlife, Hatfield Marine Science Center, 2040 SE Marine Science Drive, Newport, \\ Oregon 97365, USA
}

${ }^{2}$ Present address: National Institute of Water and Atmospheric Research, Private Bag 14901, Wellington 6241, New Zealand

\begin{abstract}
Black rockfish Sebastes melanops are generally associated with benthic structure, but are also described as semi-pelagic and are frequently found near the surface. We described patterns associated with the vertical movements of 33 black rockfish using acoustic telemetry in the nearshore waters of the Northeast Pacific Ocean off Newport, Oregon (9 to $45 \mathrm{~m}$ depth). The fish were monitored by an array of 18 moored receivers for a 12 mo period. Black rockfish showed larger, more frequent, and more temporally structured vertical movements throughout the study period than are typically assumed for rockfishes, which may make hydroacoustic surveys difficult to design. Diel vertical movements occurred sporadically, with individuals sometimes being shallower either during day or at night, and the pattern was often maintained for more than a week. Periods of large vertical movements (multiple excursions $>5 \mathrm{~m}$ not in synch with diel phase) were most common during the months of October and May. The diel behavior of being shallower at night was most common during spring months and showed a slow decline in prevalence throughout the summer months. The reverse pattern (shallower depths during daylight hours) was less common overall, but most prevalent in autumn. These data show that black rockfish make extensive vertical movements, often tightly in phase with sunrise or sunset, and that several behaviors, such as diel vertical migration, may be more prevalent at certain times of the year.
\end{abstract}

KEY WORDS: Diurnal $\cdot$ Behavior $\cdot$ Acoustic telemetry $\cdot$ Diel

\section{INTRODUCTION}

As their common name implies, rockfishes Sebastes spp. are typically tightly associated with benthic structure (Love et al. 2002). Exceptions exist, especially for continental shelf species such as widow rockfish S. entomelas, yellowtail rockfish S. flavidus, and chilipepper rockfish $S$. goodei, which are often captured in mid-water trawl fisheries and observed in pelagic schools (Wilkins 1986, Pearcy 1992, Stanley et al. 1999, 2000, Parker et al. 2000). The black rockfish S. melanops is also a semi-pelagic species, although it typically inhabits waters shallower than $55 \mathrm{~m}$ from central California to the Aleutian Islands (Love et al. 2002). Because rockfishes have a physoclistic swimbladder, they are subject to decompression injuries from exces- sive vertical movements, especially at these shallow depth scales (Parker et al. 2006). This potential for injury should limit the extent of rapid vertical excursions, especially as they approach the surface where gas volume increases by $50 \%$ between 20 and $10 \mathrm{~m}$ depth, and doubles in the final $10 \mathrm{~m}$. This physical constraint suggests limited or slow vertical movements, especially if approaching the surface.

There has been considerable interest in developing a hydroacoustic survey for black rockfish to take advantage of their semi-pelagic distribution (Boettner \& Burton 1990, Pedersen \& Boettner 1992, Alaska Department of Fish and Game unpubl. data). Significant vertical movements, especially if occurring nonrandomly and by various segments of the population, can influence availability to sonar and could bias 
hydroacoustic survey biomass estimates. These surveys also rely on the ability to distinguish midwater targets from the bottom echo return, which may not be possible if black rockfish spend significant time resting on the bottom, as sometimes observed in SCUBA surveys (Love et al. 2002). Conversely, because much of their range is shallower than $25 \mathrm{~m}$, significant time spent within a few meters of the surface also renders black rockfish undetectable by downwardly aimed hydroacoustic devices (Krieger et al. 2001). Knowledge of the vertical distribution of black rockfish is necessary to determine whether the proportion of the population undetectable at a given time is uniform, or, if variable, to determine whether their vertical movements show predictable patterns.

As targets of both recreational and commercial fisheries, and because they live in relatively shallow water, there is significant observational information from divers and fishers on black rockfish behavior patterns, movement, and habitat associations (Leaman 1977, McElderry 1979). These observations suggest they may move to the surface relatively quickly and that they tend to be inactive and rest on or near the bottom at night, at least in shallow kelp forest habitats (Love et al. 2002). However, these observations are of very short duration and consist of groups of fish, not individuals. The goal of the present study was to characterize the vertical movements of individual black rockfish in open-coast reef habitats using acoustic telemetry. Knowledge of these patterns will aid in designing survey methods and in understanding the role of black rockfish in nearshore ecosystems. Our specific objectives were to quantify the scale, frequency, duration, stability, and population-level coherence of vertical movements on an annual time scale and to correlate environmental conditions with selected movement patterns.

\section{MATERIALS AND METHODS}

This study was conducted in the Pacific Ocean near Newport, Oregon, at depths of 9 to $40 \mathrm{~m}$ as part of a telemetry study of home range size (Fig. 1, Parker et al. 2007). We monitored the study site using a rectangular array of 18 VR2 $69 \mathrm{kHz}$ omni-directional acoustic receivers (Vemco Ltd.) arranged to monitor for transmitters in a $15 \mathrm{~km}^{2}$ area. The receivers were individually anchored on single buoy lines approximately $5 \mathrm{~m}$ off bottom. The receivers recorded tag code, receiver number, date, time, and depth of the transmitter at a known location. Range testing showed a normal detection range of 350 to $500 \mathrm{~m}$ radius, and receivers were spaced approximately $700 \mathrm{~m}$ apart to allow tags to be detected by $>1$ receiver.
Black rockfish Sebastes melanops were captured by barbless hook and line fishing throughout the study area using typical recreational fishing gear on 7 occasions from August 2004 through February 2005. Fish were tagged with surgically implanted transmitters and released at capture sites throughout the monitored area to maximize habitats studied and to minimize transmission interference from multiple tags in the same area (for details, see Parker et al. 2007). Coded acoustic V-13 HP transmitters (Vemco Ltd., $69 \mathrm{kHz}$, pressure sensitive [0 to $50 \mathrm{~m}$ ] $155 \mathrm{~dB}$ output, $13 \times$ $42 \mathrm{~mm}$, vertical precision $<0.25 \mathrm{~m}$ ) were programmed to transmit at a random period of between 30 and $90 \mathrm{~s}$, with a nominal battery life of 6 mo.

Periodically, when weather allowed, we downloaded the receivers and replaced any missing receivers. Fish were assumed to be alive on a given day if some evidence of vertical movement beyond a continuous tidal

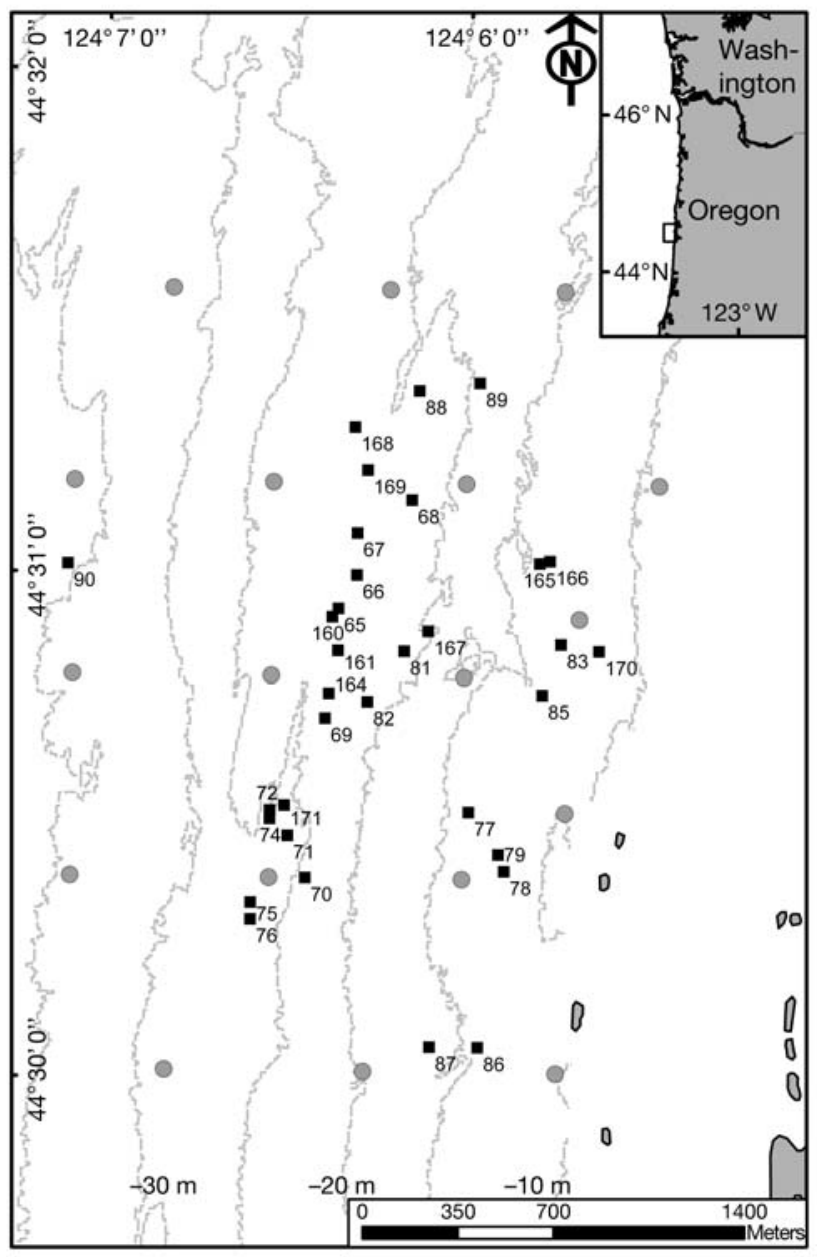

Fig. 1. Study area showing locations of 18 acoustic receivers off Seal Rock, OR, and $5 \mathrm{~m}$ bathymetric contours. Initial locations of released fish Sebastes melanops for each identification number ( $\square)$; locations of acoustic receiver moorings (O); $5 \mathrm{~m}$ depth contours (--); inset: study area location on Oregon coast 
rhythm was apparent in the depth data (tidal range $=$ $\sim 3 \mathrm{~m}$ ) after that day. Environmental observations at the time of each detection, including photoperiod, lunar day, tide stage, wave height, solar irradiance at Newport, cloud cover, water temperature at Seal Rock, and daily east and north upwelling, were obtained from standard tables, formulas, or acquired from Oregon State University, the NOAA National Weather Service, Pacific Fisheries Environmental Laboratory, or the US Naval Observatory (http://hmsc.oregonstate.edu/ weather/, http://ndbc.noaa.gov/, http://las.pfeg.noaa. gov and http://aa.usno.navy.mil/).

Plots of vertical movements were generated for each fish, and the movement pattern for each $24 \mathrm{~h}$ period was categorized to the most detailed level possible (Table 1). These daily patterns were then analyzed with respect to prevailing environmental conditions and with the movement patterns of other tagged black

Table 1. Sebastes melanops. Category definitions describing vertical movements occurring during each $24 \mathrm{~h}$ period for black rockfish off Seal Rock, OR, from August 2004 through August 2005

\begin{tabular}{|c|c|c|}
\hline Abbreviation & Behavior type & Description \\
\hline BT & Bottom tending & $\begin{array}{l}\text { Bottom-oriented } \\
\text { behavior which } \\
\text { resembled a tidal } \\
\text { pattern for most of the } \\
24 \mathrm{~h} \text { period }\end{array}$ \\
\hline LV & $\begin{array}{l}\text { Large vertical } \\
\text { movement }\end{array}$ & $\begin{array}{l}\text { Frequent vertical } \\
\text { movements exceeding } \\
5 \mathrm{~m} \text { in scale through- } \\
\text { out the } 24 \mathrm{~h} \text { period }\end{array}$ \\
\hline SV & $\begin{array}{l}\text { Small vertical } \\
\text { movement }\end{array}$ & $\begin{array}{l}\text { Frequent vertical } \\
\text { movements }<5 \mathrm{~m} \text { in } \\
\text { scale throughout the } \\
24 \mathrm{~h} \text { period }\end{array}$ \\
\hline $\mathrm{SN}$ & $\begin{array}{l}\text { Shallower } \\
\text { during night }\end{array}$ & $\begin{array}{l}\text { Vertical movements } \\
\text { partitioned during the } \\
\text { diel cycle where there } \\
\text { was a distinct shift to a } \\
\text { shallower depth } \\
\text { during hours of } \\
\text { darkness }\end{array}$ \\
\hline $\mathrm{SD}$ & $\begin{array}{l}\text { Shallower } \\
\text { during day }\end{array}$ & $\begin{array}{l}\text { Vertical move- } \\
\text { ments partitioned } \\
\text { during the diel cycle } \\
\text { where there was a } \\
\text { discrete shift to a } \\
\text { shallower depth } \\
\text { during hours of } \\
\text { daylight }\end{array}$ \\
\hline Other & Uncategorized & $\begin{array}{l}\text { Days lacking enough } \\
\text { observations to } \\
\text { categorize behavior as } \\
\text { any of the other } \\
\text { behaviors }\end{array}$ \\
\hline
\end{tabular}

rockfish. Descent and ascent rates were calculated by sorting records by date, time, tag number, and receiver number, calculating the time elapsed between successive records and normalizing to a per minute standard, providing a minimum vertical movement rate.

Because there were many fish simultaneously at large, we looked for coherence in daily behavior patterns among fish. Coherence in behavior patterns among fish was summarized by calculating the percentage of observed fish showing a particular behavior pattern on a given day. Daily behaviors were categorized visually based on a detailed depth trace, which also included photoperiod information.

Periodicity in vertical movements was evaluated using a Lomb-Scargle periodogram to identify significant rhythms in vertical movements occurring with periods between 5 and $30 \mathrm{~h}$, available as a routine in $\mathrm{R}$ (for details see Ruf 1999). Sample size requirements prohibited analyses searching for cycles with longer periods (weeks or months), as the data series must contain observations spanning at least 10 cycles of interest for adequate statistical power.

\section{RESULTS}

Thirty-three black rockfish Sebastes melanops (34 to $46 \mathrm{~cm}$ total length [TL]) were tagged with depth transmitters and released within the array during 7 tagging days within a 7 mo period (Table 2, Fig. 1). From the appearance of external genitalia, we determined that 15 of these fish were females. Based on length at maturity curves, it is likely that only 10 of the females were reproductively mature $(>39 \mathrm{~cm}$ ) (Bobko \& Berkeley 2004).

We recorded $>3$ million detections between August 4, 2004 and November 14, 2005. We observed no evidence in the pressure data indicating that any fish had died within the array. However, 3 fish left the array and did not return during the 6 mo period that the transmitter was expected to be functional (IDs 87, 166, 167). These 3 fish still provided 79 to $138 \mathrm{~d}$ of information. Although nominal transmitter life was 6 mo, most lasted 10 mo and some provided information for nearly 1 yr (Table 2).

The daily variance in depth for each fish plotted for the entire study period shows a pulse in range of vertical movement from September through November in 2004 and 2005, and a series of 3 short pulses during the summer months (Fig. 2). In general, vertical movements were smaller in the winter. Minimum rates of ascent and descent had identical ranges, with $>99 \%$ of the values $<14 \mathrm{~cm} \mathrm{~s}^{-1}$, equivalent to $8.4 \mathrm{~m} \mathrm{~min}^{-1}$. The ratio of ascents to descents versus speed of the movement showed that fast movements $\left(>15 \mathrm{~m} \mathrm{~min}^{-1}\right)$ were 
Table 2. Sebastes melanops. Summary data of 33 black rockfish tagged and released off Seal Rock, OR, from August 4, 2004 through November 15, 2005

\begin{tabular}{|c|c|c|c|c|c|c|c|}
\hline $\begin{array}{l}\text { Fish } \\
\text { ID }\end{array}$ & $\begin{array}{l}\text { Date range } \\
\text { (mm/dd) }\end{array}$ & $\begin{array}{l}\text { Length } \\
\text { (cm) }\end{array}$ & Gender & $\begin{array}{l}\text { Duration } \\
\text { (d) }\end{array}$ & $\begin{array}{l}\text { Max. } \\
\text { depth } \\
(\mathrm{m})\end{array}$ & $\begin{array}{l}\text { Min. } \\
\text { depth } \\
\text { (m) }\end{array}$ & $\begin{array}{l}\text { Annual mean } \\
\text { depth } \\
\text { (m) }\end{array}$ \\
\hline 65 & 08/04-04/19 & 36 & M & 259 & -28.5 & 0.0 & -19.3 \\
\hline 66 & 08/04-04/11 & 42 & $\mathrm{~F}$ & 251 & -26.4 & -0.6 & -11.0 \\
\hline 67 & 08/04-07/09 & 40 & $\mathrm{M}$ & 340 & -34.2 & -0.3 & -26.0 \\
\hline 68 & 08/04-06/03 & 40 & M & 304 & -44.6 & 0.0 & -12.4 \\
\hline 69 & 09/21-08/16 & 45 & M & 330 & -36.4 & -0.3 & -21.1 \\
\hline 70 & 09/21-08/16 & 43 & M & 330 & -35.7 & -0.6 & -20.3 \\
\hline 71 & 09/21-08/01 & 42 & M & 315 & -33.0 & -5.1 & -23.0 \\
\hline 72 & $09 / 21-05 / 21$ & 41 & $\mathrm{~F}$ & 243 & -37.1 & -1.6 & -21.1 \\
\hline 74 & 09/21-07/12 & 43 & M & 295 & -39.6 & -3.4 & -27.8 \\
\hline 75 & 09/21-07/13 & 41 & M & 296 & -42.6 & -1.2 & -24.0 \\
\hline 76 & 09/21-03/31 & 46 & $\mathrm{~F}$ & 192 & -35.9 & -4.4 & -28.0 \\
\hline 77 & $09 / 21-05 / 29$ & 45 & $\mathrm{~F}$ & 251 & -32.7 & -0.3 & -18.6 \\
\hline 78 & 09/21-08/16 & 39 & M & 330 & -37.8 & -0.3 & -11.3 \\
\hline 79 & $09 / 21-03 / 28$ & 36 & M & 189 & -21.0 & -1.3 & -13.2 \\
\hline 81 & $09 / 23-07 / 12$ & 34 & M & 293 & -31.0 & -2.8 & -18.9 \\
\hline 82 & $09 / 23-07 / 25$ & 34 & M & 306 & -31.0 & -1.2 & -15.0 \\
\hline 83 & $10 / 04-07 / 16$ & 39 & M & 286 & -30.2 & -0.9 & -15.4 \\
\hline 85 & $10 / 04-08 / 15$ & 40 & $\mathrm{~F}$ & 316 & -33.4 & -0.6 & -6.6 \\
\hline 86 & $10 / 04-07 / 22$ & 35 & F & 292 & -28.0 & -0.3 & -11.1 \\
\hline 87 & $10 / 04-01 / 30$ & 40 & F & 119 & -27.1 & -0.6 & -9.3 \\
\hline 88 & $10 / 04-08 / 16$ & 40 & $\mathrm{~F}$ & 317 & -31.1 & -3.1 & -14.9 \\
\hline 89 & $10 / 04-08 / 08$ & 46 & $\mathrm{~F}$ & 309 & -36.0 & -0.6 & -12.0 \\
\hline 90 & $10 / 04-08 / 16$ & 45 & $\mathrm{~F}$ & 317 & -44.8 & -0.9 & -34.2 \\
\hline 160 & $08 / 04-12 / 19$ & 41 & $\mathrm{~F}$ & 138 & -30.1 & -0.6 & -16.8 \\
\hline 161 & $08 / 04-12 / 16$ & 40 & M & 135 & -27.0 & -0.6 & -12.0 \\
\hline 164 & $02 / 15-08 / 16$ & 37 & M & 183 & -30.3 & -0.6 & -10.4 \\
\hline 165 & $02 / 24-08 / 16$ & 38 & M & 174 & -21.0 & 0.0 & -12.0 \\
\hline 166 & $02 / 24-05 / 13$ & 37 & $\mathrm{~F}$ & 79 & -18.8 & 0.0 & -7.4 \\
\hline 167 & $02 / 15-07 / 02$ & 38 & F & 138 & -25.7 & -3.4 & -12.1 \\
\hline 168 & $02 / 25-08 / 16$ & 37 & F & 173 & -27.1 & -0.3 & -8.4 \\
\hline 169 & $02 / 25-08 / 16$ & 38 & $\mathrm{~F}$ & 173 & -30.6 & -1.2 & -15.0 \\
\hline 170 & $02 / 15-08 / 16$ & 35 & M & 183 & -18.0 & -0.3 & -3.0 \\
\hline 171 & $02 / 25-08 / 16$ & 44 & M & 173 & -36.8 & -0.9 & -16.2 \\
\hline Mean & & 39.6 & & 218 & -31.5 & -1.2 & -16.3 \\
\hline SEM & & 0.6 & & 132 & 1.2 & 0.2 & 1.2 \\
\hline
\end{tabular}

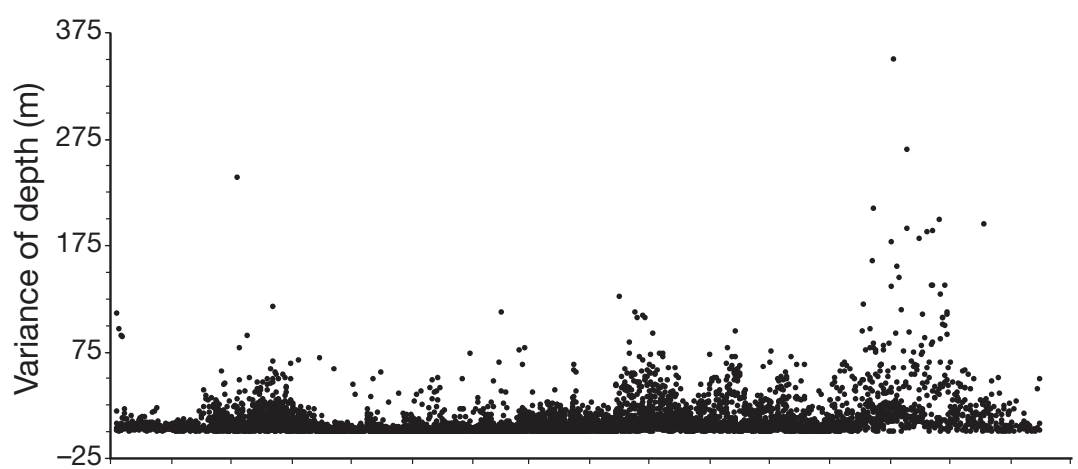

Aug Sep Oct Nov Dec Jan Feb Mar Apr May Jun Jul Aug Sep Oct Nov Dec 2004 2005

Fig. 2. Sebastes melanops. Daily variance in depth (m) for each fish from August 4, 2004 to November 15, 2005. Note: excludes 1 data point at 590.69 for Tag ID 171 on August 22, 2005
10 to $50 \%$ more likely to be dives, whereas movements slower than $15 \mathrm{~m}$ $\min ^{-1}$ were equally likely to be descents or ascents. Vertical movement rates were different depending on starting depth (Fig. 3). The fastest ascents began at depths of 40 to $50 \mathrm{~m}$ (log-transformed ANOVA, $\mathrm{p}<0.0001$ ), whereas the fastest descents occurred at starting depths of 0 to $10 \mathrm{~m}$ (logtransformed ANOVA, p $<0.0001$ ). Long periods between detections were few $190 \%$ of observations were $<10$ min apart), bias in dive rates was negligible, and no change in pattern with depth was observed by including all the data.

We also observed multi-day periods in which the depth of a fish varied directly with the tidal cycle, indicating it was either on the bottom or maintaining a fixed position in the water column relative to the bottom. This behavior was termed bottom tending (BT) (Fig. 4A) and was displayed intermittently by most fish, with the behavior much more common among a few fish (Table 3). BT behavior was observed for up to 9 contiguous days, but typically it was observed for only a single day at a time. Common examples of BT behavior may be due to a recovery period following surgery and release. Of the 33 fish, 8 did not show BT behavior during the first $10 \mathrm{~d}$. Of the 25 fish that did, 21 fish showed BT behavior for between 2 and $4 \mathrm{~d}$, with most fish at 2 d. Substantial and frequent vertical movements were apparent in all individuals throughout the study. No fish showed a continuous tidal pattern in depth which would indicate that the fish had died.

We observed several patterns in vertical movements. At a coarse level, black rockfish were typically very active vertically (Fig. 4B), moving often between the bottom and midwater (10 to $15 \mathrm{~m}$ depth), and sometimes reaching the surface. These ascents and dives were often incessant and lasted for days. We classified this behavior as large vertical movements (LV) as there was no obvious finer pattern in the daily frequency, 


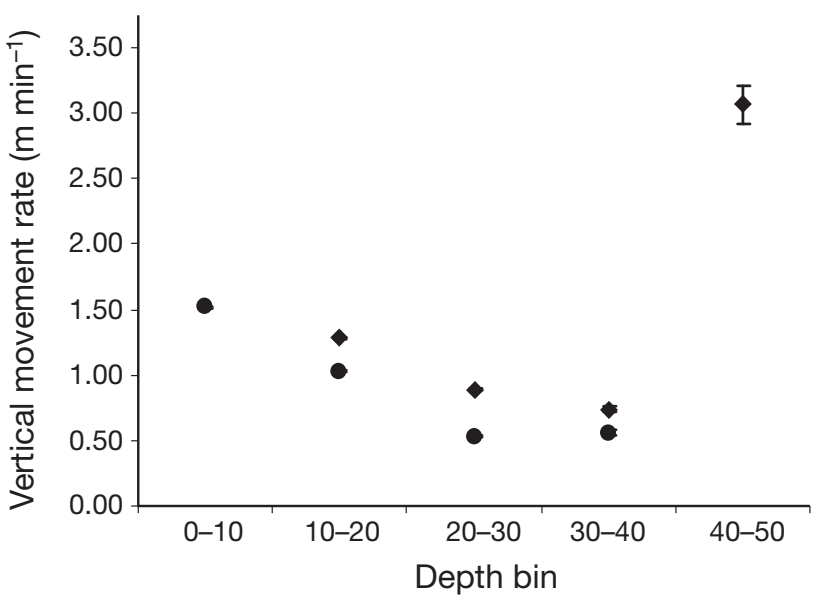

Fig. 3. Sebastes melanops. Mean ascent $(\bullet)$ and descent $(\bullet)$ rates $\left(\mathrm{m} \mathrm{min}^{-1}\right)$ for movements beginning at different depth ranges from 0 to $50 \mathrm{~m}$. Movements near boundaries (ascents beginning at 0 to $10 \mathrm{~m}$ and descents beginning at 40 to $50 \mathrm{~m}$ ) are not meaningful and therefore omitted. Error bars: SEM
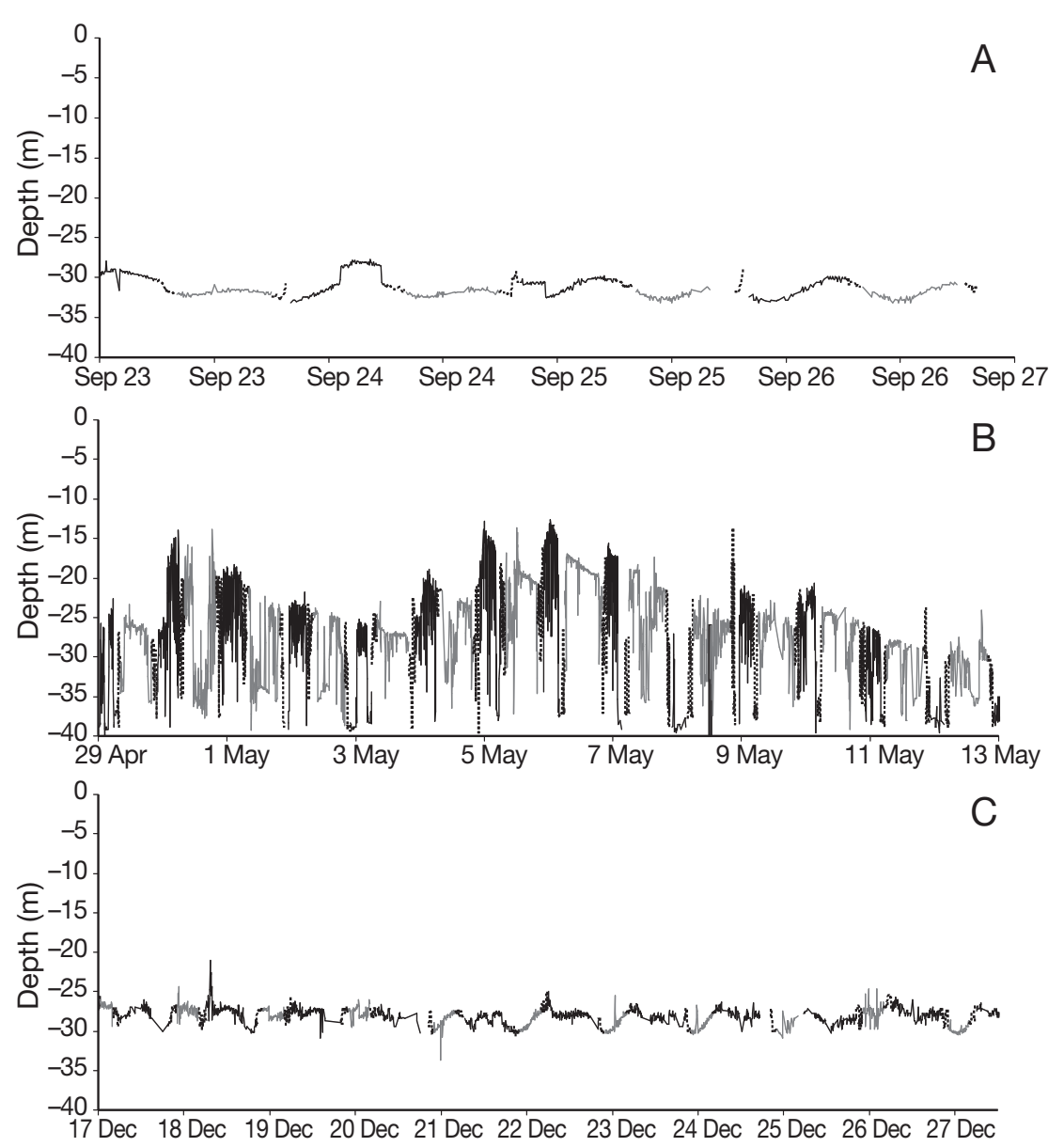

Fig. 4. Sebastes melanops. Examples of black rockfish behaviors observed between August 4, 2004 and November 15, 2005. Black line segments: night; grey lines: daylight; dotted lines: crepuscular periods (within $1 \mathrm{~h}$ of sunrise or sunset). Zero depth represents the surface. (A) Bottom tending behavior, ID76; (B) large vertical movements (>5 m), ID 90; and (C) small vertical movements $(<5 \mathrm{~m})$, ID 75 scale, or timing of the movements. All but 1 fish showed the LV pattern, with some doing so continuously up to $21 \mathrm{~d}$ (Table 3 ). There were, however, some distinct patterns in which fish slowly changed their minimum depth over several days (Fig. 4B), raising interesting questions about how they repeatedly return to the same minimum depth, even at night (Fig. 5A).

At other times, fish made small vertical movements $<5 \mathrm{~m}(\mathrm{SV})$, but did not remain a constant height off bottom. When this behavior occurred very close to the ottom, the depth profile showed a noisy sinusoidal ce of the tidal signal, generated when the fish's relaip to bottom was fairly constant. One fish showed various depths, but showed

(Fig. 4C).

Several, more complex, vertical movement patterns were observed. Patterns of ascending to shallower (SN) as well as patterns with regular the day (SD) were frequently observed (Fig. 5). This pattern was defined graphically by a shift in mean depth between day and night, with a small degree of variation around that mean. The timing of the major vertical movements was often tightly correlated with sunrise and sunset, even though photoperiod phase duration changes throughout the year. But there were also examples where the daily depth change was not associated with sunrise or sunset (Fig. 5B). The deep phase of this pattern showed that the fish was tightly associated with the bottom, given the presence of a smooth tidal signal (Fig. 5). All fish showed a diel vertical movement pattern for several days at some point during the study, with 1 fish showing the behavior for $28 \mathrm{~d}$ continuously. The pattern was most commonly observed for a single day, but often lasted more than a week before dissolving or morphing into another behavior pattern.

The percentage of fish showing behaviors of LV, SV, SD, SN, and BT was summarized for each day. These behaviors were mutually exclusive, as each $24 \mathrm{~h}$ period was assigned 1 behavior. The 'other' category was used to classify days in which the number of detections was too few to describe a movement pattern for the day and includes days with no detections. Most fish showed all 
Table 3. Sebastes melanops. Summary of percent of days showing categorized behavior types observed from black rockfish tagged and released off Seal Rock, OR, from August 4, 2004 through November 15, 2005. Max. days indicates maximum number of contiguous days an individual fish showed the particular behavior pattern. Abbreviations of behavior types: see Table 1

\begin{tabular}{|c|c|c|c|c|c|c|}
\hline Fish ID & BT & $\mathrm{SD}$ & SN & LV & SV & Other \\
\hline 65 & 5.4 & 11.6 & 1.2 & 23.2 & 13.1 & 45.6 \\
\hline 66 & 4.0 & 6.0 & 6.8 & 32.3 & 17.9 & 33.1 \\
\hline 67 & 26.3 & 14.8 & 2.7 & 8.9 & 40.2 & 7.1 \\
\hline 68 & 4.1 & 2.4 & 39.7 & 33.9 & 11.9 & 8.1 \\
\hline 69 & 17.9 & 7.9 & 3.3 & 13.9 & 27.9 & 29.1 \\
\hline 70 & 3.9 & 8.5 & 31.2 & 32.4 & 11.8 & 12.1 \\
\hline 71 & 8.6 & 13.4 & 2.2 & 21.3 & 39.5 & 15.0 \\
\hline 72 & 7.8 & 6.2 & 9.5 & 21.4 & 32.1 & 23.0 \\
\hline 74 & 41.6 & 8.4 & 2.0 & 6.8 & 6.8 & 34.5 \\
\hline 75 & 18.6 & 4.7 & 45.6 & 20.9 & 4.4 & 5.7 \\
\hline 76 & 33.9 & 7.3 & 10.4 & 8.9 & 15.6 & 24.0 \\
\hline 77 & 13.1 & 0.0 & 1.2 & 9.2 & 12.4 & 64.1 \\
\hline 78 & 0.9 & 6.1 & 23.9 & 23.6 & 17.3 & 28.2 \\
\hline 79 & 4.8 & 4.8 & 2.1 & 7.9 & 28.0 & 52.4 \\
\hline 81 & 0.0 & 2.7 & 0.0 & 3.8 & 8.5 & 85.0 \\
\hline 82 & 0.3 & 0.0 & 0.3 & 9.5 & 12.4 & 77.5 \\
\hline 83 & 6.6 & 18.9 & 6.6 & 5.9 & 49.3 & 12.6 \\
\hline 85 & 0.3 & 2.3 & 3.6 & 14.9 & 4.0 & 74.8 \\
\hline 86 & 2.2 & 0.9 & 37.5 & 6.3 & 43.3 & 9.8 \\
\hline 87 & 0.9 & 1.7 & 6.1 & 0.0 & 11.3 & 80.0 \\
\hline 88 & 0.0 & 1.9 & 0.3 & 0.6 & 26.8 & 70.3 \\
\hline 89 & 0.3 & 1.6 & 21.4 & 14.6 & 19.4 & 42.7 \\
\hline 90 & 6.3 & 28.4 & 2.2 & 13.9 & 21.1 & 28.1 \\
\hline 160 & 8.0 & 30.4 & 5.1 & 26.8 & 10.1 & 19.6 \\
\hline 161 & 5.2 & 15.6 & 3.7 & 23.7 & 31.1 & 20.7 \\
\hline 164 & 1.1 & 3.3 & 26.8 & 29.0 & 9.8 & 30.1 \\
\hline 165 & 34.5 & 9.8 & 6.9 & 13.2 & 20.1 & 15.5 \\
\hline 166 & 3.8 & 8.9 & 54.4 & 11.4 & 20.3 & 1.3 \\
\hline 167 & 0.0 & 0.7 & 1.4 & 6.5 & 8.0 & 83.3 \\
\hline 168 & 1.2 & 1.2 & 58.4 & 27.7 & 8.1 & 3.5 \\
\hline 169 & 3.5 & 4.6 & 34.7 & 16.2 & 3.5 & 37.6 \\
\hline 170 & 0.5 & 1.1 & 31.9 & 15.4 & 25.3 & 25.8 \\
\hline 171 & 4.6 & 5.8 & 12.7 & 13.9 & 1.7 & 61.3 \\
\hline Mean & 8.2 & 7.3 & 15.0 & 15.7 & 18.6 & 35.2 \\
\hline SEM & 1.9 & 1.3 & 3.0 & 1.6 & 2.2 & 4.5 \\
\hline Max. days & 9 & 19 & 28 & 21 & 29 & 73 \\
\hline
\end{tabular}

behaviors at some point, but did so for variable periods (Table 3). Summarizing for all fish, the behaviors categorized were split about evenly among SV, LV, and $\mathrm{SN}$, with fewer observations of SD and BT behaviors, though this ignores some individuals with contrasting behavior patterns (e.g. ID 74). We note that because the 'other' category represented a significant portion of the days observed, some behaviors may be underestimated if the behavior decreased the probability of detection (e.g. acoustic transmissions may be obscured when in close proximity to complex substrate, as in BT).

The analysis shows coherence among individuals with sometimes $>60 \%$ of the observed fish performing the same behavior pattern for multiple days. In addition, although multi-day pulses in coherence are apparent, the degree of coherence changed gradually throughout the year, especially for $\mathrm{SN}$, which peaked in late April and gradually declined to zero in late September (Fig. 6). SD behavior showed several pulses throughout the study period at various intervals. Short vertical movements dominated all behaviors during winter months, and large vertical movements were most prevalent from September through November (Fig. 6). A generalized pattern of more SV behavior occurred during winter months, and the largest peak in LV behavior was in September and October (Fig. 6). Only the BT behavior changed with respect to lunar phase, being much less common during new moon (transformed ANOVA, p < 0.001).

Periodogram analysis of 28 black rockfish with sufficient data showed that they all had a significant diel rhythm in vertical movement, with a dominant period of $23.939 \pm 0.050 \mathrm{~h}(\mathrm{p}<0.05)$. One fish, with a low dominant period length of $23.205 \mathrm{~h}$, also had an additional significant period at $24.000 \mathrm{~h}$ (ID 165). Three of the fish (those with the lowest sample sizes) showed multiple significant periods near $24 \mathrm{~h}$, but with slightly more variable dominant periods $(23.448,24.662$, and $23.419 \mathrm{~h}$ ). In addition to diel rhythms, 13 fish showed a significant rhythm in vertical movement, with a mean period of $12.354 \pm 0.040 \mathrm{~h}(\mathrm{p}<0.05)$, suggesting vertical movements linked to the tidal cycle. We detected no significant correlation between the recorded environmental variables (wave height, solar irradiance at Newport, cloud cover, water temperature at Seal Rock, or daily east and north upwelling) and normalized depth, variance of depth, or any of the categorized behaviors.

\section{DISCUSSION}

Black rockfish Sebastes melanops showed larger, more frequent, and more temporally structured vertical movements throughout the 12 mo study period than have been reported in the literature based on video or diver observations (Leaman 1977, McElderry 1979). Direct or video observations are severely limited in duration, especially on individual fish, with the result being that movement patterns over more than a few minutes, especially at night or in variable weather, have not been observed. This behavior is surprising because black rockfish possess a closed swimbladder and live in relatively shallow water, making them especially susceptible to injury due to swimbladder gas expansion during ascents (Parker et al. 2006). McElderry (1979) showed that black rockfish swimbladders cannot expand more than approxi- 

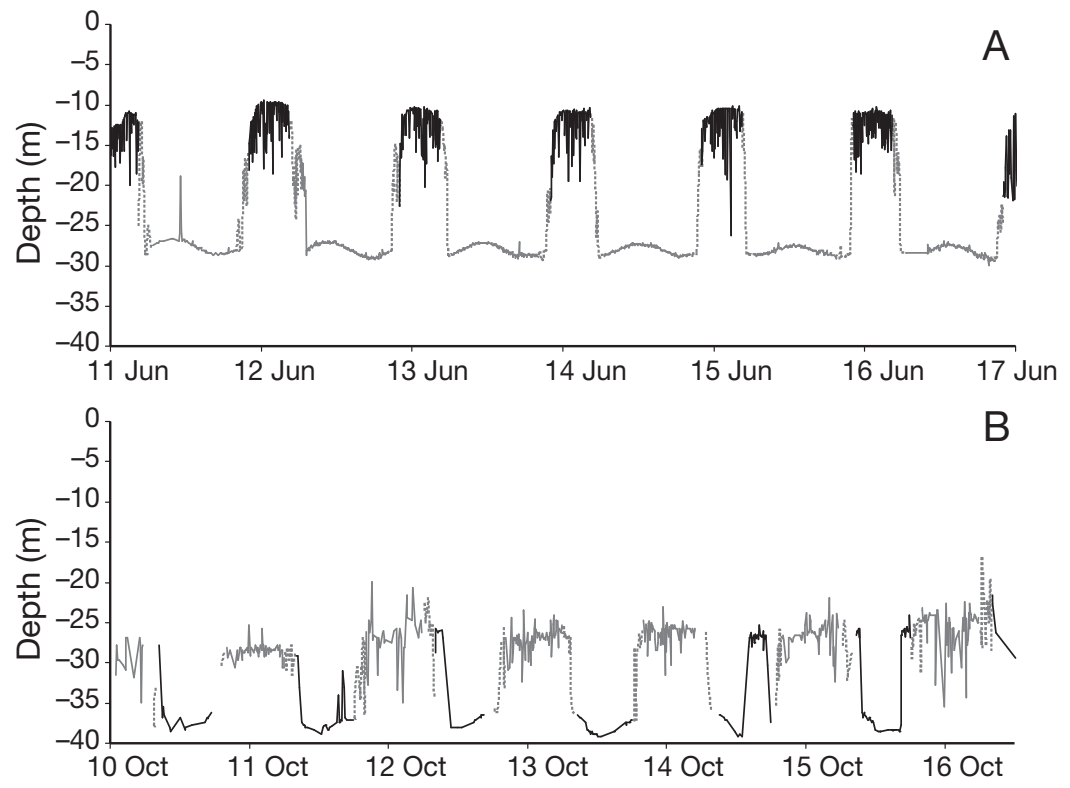

Fig. 5. Sebastes melanops. Examples of diel vertical migration. Black, greyscale and dotted lines as in Fig. 4. (A) Depth shallower during night phase, ID 75, and (B) depth shallower during the day phase, ID 90

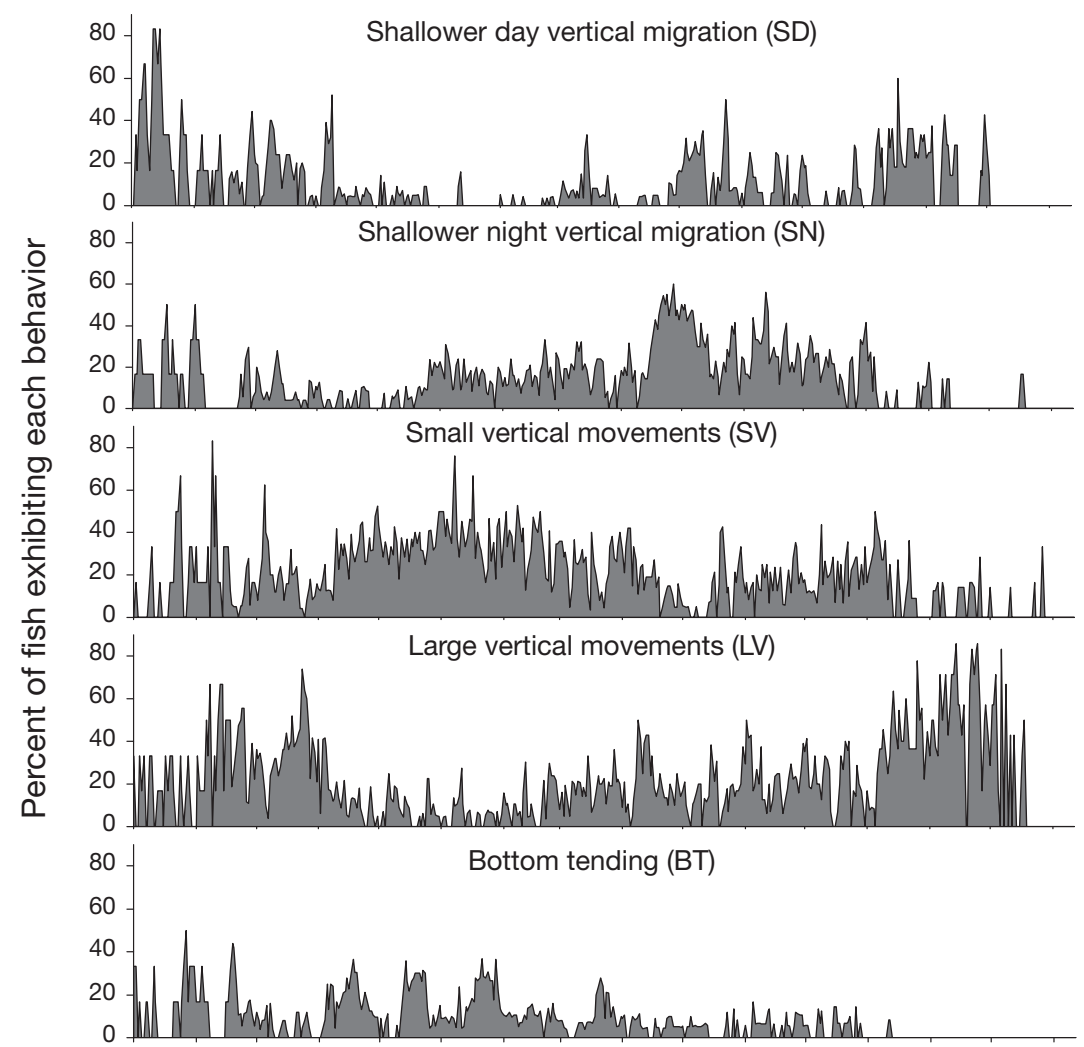

Aug Sep Oct Nov Dec Jan Feb Mar Apr May Jun Jul Aug Sep Oct Nov 2004 2005

Fig. 6. Sebastes melanops. Behavioral coherence (the percentage of fish observed showing a particular behavior) on a daily basis for fish showing 5 categorized behaviors mately $60 \%$ in volume prior to rupture. In addition, hyperbaric chamber experiments resulted in rupture of swimbladders in $100 \%$ of black rockfish exposed to a $90 \mathrm{~s}, 3$ ATA (absolute atmospheres) decrease in pressure followed by 2 min at surface pressure-a 300\% increase in gas volume (Parker et al. 2006). Because we observed larger (>30 m) and faster (<2 min) movements (e.g. Fig. 4B) than those simulated in the hyperbaric chamber experiments, we conclude that black rockfish maintain their swimbladders so that neutral buoyancy occurs at a much shallower depth than the bottom. The actual volume of the black rockfish swimbladder in nature has not been determined, but black rockfish have been acclimated to neutral buoyancy at a particular depth in hyperbaric aquaria (Parker et al. 2006). Combined, this suggests that black rockfish are constantly, but slowly, acclimating to their depth at any moment. Because removing gas from the swimbladder is much faster than adding gas (Parker et al. 2006), the neutral depth of a vertically active fish will be consistently shallower than its actual depth.

The degree of vertical activity was also surprising given the relatively small horizontal movements observed in other studies (Culver 1987, Parker et al. 2007). Fish with a small home range (average of $0.55 \mathrm{~km}^{2}$ from Parker et al. 2007) would not be expected to spend significant time off bottom in an environment with continuous currents sometimes exceeding $1 \mathrm{~m} \mathrm{~s}^{-1}$ (Kosro 2005). Black rockfish behavior could be characterized as utilizing the vertical dimension of their habitat more than the horizontal dimension. This close association to a home site while making significant vertical movements is unusual, as most fishes with small home ranges are linked to a territory (Keenleyside 1979), patchy habitat (Matthews 1990), or are associated with midwater structures such as kelp beds (Lowe et al. 2003). It is likely that black rockfish maintain their relatively small horizontal home ranges by frequently diving to bottom for spatial reference. However, our data frequently 
show long periods, both during daylight and darkness, when an individual fish maintained its position while in midwater, likely in a shoal (e.g. Fig. 5A). Pitcher \& Parrish (1993) described many of the evolutionary pressures that may shape shoaling behavior. While some apply to black rockfish behaviors, such as foraging efficiency, it is also possible that black rockfish maintain a geographic position while in low-visibility conditions in midwater by remaining near conspecifics in a shoal, so that there is always a visual link back to the substrate.

The combination of unpredictable patterns in vertical movement, maintaining the swimbladder at a smaller volume than neutral, and spending significant amounts of time in close proximity to the bottom make hydroacoustic surveys of black rockfish problematic. Our data suggest that a constant or predictable portion of the population is not detectable by sonar at any time and that signal strength data will vary depending on both the depth of the individual and the recent vertical activity pattern of that individual fish.

We documented a seasonal pattern in the variability of vertical movements, suggesting that, during winter months, vertical activity is reduced and more time is spent in close proximity to the bottom. The timing of this reduction in variance is associated with an increase in wave height from winter storms, though there was a period in August and September where reduced vertical activity was observed. Inversely, the pattern could be described as pulsed periods of increased activity (fall and spring months), with a longer period of reduced vertical movement.

We recorded vertical position every 30 to $90 \mathrm{~s}$; minimum vertical movement rates were almost exclusively $<8.4 \mathrm{~m} \mathrm{~min}^{-1}$ or $14 \mathrm{~cm} \mathrm{~s}^{-1}$. Still, at $8 \mathrm{~m}$ $\mathrm{min}^{-1}$, gas expansion would be much faster than gas removal abilities, and injury could occur. Parker et al. (2006) showed that black rockfish acclimated to $30 \mathrm{~m}$ showed significant barotrauma signs during a $90 \mathrm{~s}$ ascent to the surface, whereas these field data show minimum ascent rates of $16 \mathrm{~m}$ in $2 \mathrm{~min}$. Most of the observations in the present study occurred at bottom depths of $<40 \mathrm{~m}$, where the gas expansion is most extreme. Ascent rates were fastest at deeper depths, where gas expansion was minimal, and descent rates were fastest near the surface, where gas compression is maximal, suggesting that black rockfish display the most freedom of movement in situations where problems associated with gas expansion are minimized.

At some point during the study, every fish showed a diurnal vertical migration pattern. This was most often distinguishable for only a single day at a time, but was commonly observed for 2 to 6 contiguous days by various individuals during the observation period. Our ability to detect this pattern graphically was often limited by large numbers of quick ascents and dives superimposed on the general pattern of a change in mean depth during 1 phase of the photoperiod (Fig. 4). Often a SD or SN behavior pattern faded into an LV pattern as the variance in vertical movements increased. However, the periodogram analysis showed the long-term, dominant $24 \mathrm{~h}$ rhythm in depth for each fish. The timing of the vertical movements in the SN or SD patterns was not always associated with sunrise or sunset, though it was usually within a few hours, indicating their movements were not a response solely to changes in light level. Our analysis also suggested a circatidal period in vertical movements for some fish. We consider this probable, but it is confounded by the amount of time that fish remained in close contact with the bottom, which would tend to create a $12.4 \mathrm{~h}$ rhythm in depth as the water rose and fell above them. Countering this effect is the large amount of vertical movement observed by almost all fish throughout the entire study. When fish are off bottom, they do not regulate their depth with reference to the bottom, so any pattern in depth is volitional. As only 11 fish showed this periodicity, and it is not possible to determine when a fish was close enough to the bottom to influence its choice of depth, additional information is needed to address these 2 possibilities.

Seasonal patterns in behavioral coherence in activity suggest that black rockfish are responding to local external stimuli as opposed to an internal rhythm or a more global environmental cue, such as photophase. Activity regulated by an internal clock would occur in the majority of individuals, and more coherence would be expected than we observed. More localized environmental information, such as patchy prey availability (e.g. schools of sand lance, ctenophores, or crab zoeae; Oregon Department of Fish and Wildlife unpubl. data) could explain a weak pattern of many fish in the study area showing the same behavior during a period lasting several days. The seasonal peaks in SN and SD behavior suggest a link to local factors that are themselves seasonal, such as the prevalence of particular prey species that are most effectively preyed upon in certain conditions.

The environmental and physiological drivers of the observed patterns in vertical movement are speculative, but the dynamic nature of the vertical movements for this rockfish species is clear. Black rockfish have developed a niche similar to semi-pelagic continental shelf species such as yellowtail and widow rockfish (Love et al. 2002), but have done so in a nearshore environment where decompression constraints and discrete habitat associations create additional pressures for behavioral adaptation. 
Acknowledgements. We thank Troy Buell, Keith Matteson, Steve Kupillas, Jon Nottage, Zeb Schobernd, Bob Hannah, and Stephen Jones for their assistance in catching fish, maintaining the array, and downloading the receivers. Christopher Romsos provided expert GIS assistance. We also thank the fishermen and beachcombers that found and returned receivers that were lost during storm events or fishing mishaps.

\section{LITERATURE CITED}

Bobko SJ, Berkeley SA (2004) Maturity, ovarian cycle, fecundity, and age-specific parturition of black rockfish, Sebastes melanops. Fish Bull 102:418-429

Boettner JF, Burton SF (1990) Hydroacoustic stock assessment study of Washington coastal black rockfish of Washington State. Tech. Report 108, Wash. Dept. of Fisheries, Olympia, WA

Culver BN (1987) Results from tagging black rockfish (Sebastes melanops) off the Washington and northern Oregon coast. In: Proceedings of the international rockfish symposium, Anchorage, Alaska. University of Alaska Sea Grant Report No. 87.2, Fairbanks, AK, p 231-240

Keenleyside MHA (1979) Diversity and adaptation in fish behavior. Springer-Verlag, Berlin

Kosro PM (2005) On the spatial structure of coastal circulation off Newport, Oregon, during spring and summer 2001 in a region of varying shelf width. J Geophys Res 110:C10S06

Krieger K, Heifetz J, Ito D (2001) Rockfish assessed acoustically and compared to bottom-trawl catch rates. Alsk Fish Res Bull 8:71-77

Leaman BM (1977) The diel activities of the black rockfish (Sebastes melanops Girard) and beds of Macrocystis integrifola Bory in Barkley Sound, BC, Canada. J Phycol 13(Suppl 1):39

Love MS, Yoklavich M, Thorsteinson L (2002) The rockfishes of the Northeast Pacific. University of California Press, Berkeley, CA

Lowe CG, Topping DT, Cartamil DP, Papastamatiou YP (2003) Movement patterns, home range, and habitat utilization of adult kelp bass Paralabrax clathratus in a temperate notake marine reserve. Mar Ecol Prog Ser 256:205-216

Matthews KR (1990) An experimental study of the habitat

Editorial responsibility: Matthias Seaman,

Oldendorf/Luhe, Germany preferences and movement patterns of copper, quillback, and brown rockfishes (Sebastes spp.). Environ Biol Fishes 29:161-178

McElderry HI (1979) A comparative study of the movement habits and their relationship to buoyancy compensation in two species of shallow reef rockfish (Pices, Scorpaenidae). MS thesis, University of Victoria

Parker SJ, Berkeley SA, Golden JT, Gunderson DR and others (2000) Management of Pacific rockfish. Fisheries 23:22-25

Parker SJ, McElderry HI, Rankin PS, Hannah RW (2006) Buoyancy regulation and barotrauma in two species of nearshore rockfish. Trans Am Fish Soc 135:1213-1223

Parker SJ, Rankin PS, Olson JM, Hannah RW (2007) Movement patterns of black rockfish (Sebastes melanops) in Oregon coastal waters. In: Heifetz J, DiCosimo J, Gharrett AJ, Love MS, O'Connell VM, Stanley RD (eds) Biology, assessment, and management of North Pacific rockfishes. Alaska Sea Grant, University of Alaska, Fairbanks, AK, p 39-57

Pearcy WG (1992) Movements of acoustically tagged yellowtail rockfish Sebastes flavidus on Heceta Bank, Oregon. Fish Bull 90:726-735

Pedersen MG, Boettner JF (1992) Application of hydroacoustic technology to marine fishery management in Washington State. Fish Res 14:209-219

Pitcher TJ, Parrish JK (1993) Functions of shoaling behavior in teleosts. In: Pitcher TJ (ed) Behavior of teleost fishes. Chapman and Hall, New York

Ruf T (1999) The Lomb-Scargle periodogram in biological rhythm research: analysis of incomplete and unequally spaced time series. Biol Rhythm Res 30:178-201

Stanley RR, Keiser R, Leaman BM, Cooke KD (1999) Diel vertical migration by yellowtail rockfish, Sebastes flavidus, and its impact on acoustic biomass estimation. Fish Bull 97:320-331

Stanley RD, Kieser R, Cooke KD, Surry AM, Mose B (2000) Estimation of a widow rockfish (Sebastes entomelas) shoal off British Columbia, Canada, as a joint exercise between stock assessment staff and the fishing industry. ICES J Mar Sci 57:1035-1049

Wilkins ME (1986) Development and evaluation of methodologies for assessing and monitoring the abundance of widow rockfish, Sebastes entomelas. Fish Bull 84: $287-310$

Submitted: June 19, 2007; Accepted: February 1, 2008 Proofs received from author(s): March 5, 2008 